Tohoku J. Exp. Med., 2007, 212, 423-430

\title{
The Pulmonary Involvement in Rheumatic Diseases: Pulmonary Effects of Ankylosing Spondylitis and Its Impact on Functionality and Quality of Life
}

\author{
Umit Dincer, ${ }^{1}$ Engin Cakar, ${ }^{1}$ M. Zeki Kiralp, ${ }^{1}$ Erkan Bozkanat, ${ }^{2}$ Hilmi Kilac ${ }^{1}$ \\ and HASAN DURSUN ${ }^{1}$ \\ ${ }^{1}$ Department of Physical Medicine and Rehabilitation, Gülhane Military Medical Academy \\ Haydarpasa Training Hospital, Istanbul, Turkey \\ ${ }^{2}$ Department of Chest Diseases, Gülhane Military Medical Academy Haydarpasa Training \\ Hospital, Istanbul, Turkey
}

Dincer, U., Cakar, E., Kiralp, M.Z., Bozkanat, E., Kilac, H. and Dursun, H. The Pulmonary Involvement in Rheumatic Diseases: Pulmonary Effects of Ankylosing Spondylitis and Its Impact on Functionality and Quality of Life. Tohoku J. Exp. Med., 2007, 212 (4), 423-430 — Rheumatic diseases are chronic inflammatory diseases which cause mild to severe functional loss and disability due to articular and extra-articular manifestations. One common form -ankylosing spondylitis (AS)- affects mainly the axial skeleton and sacroiliac joints, and certain extra-articular organs. The pulmonary involvement is a known manifestation of AS and emerges either in the form of interstitial lung disease or in the form of restricted pulmonary functions. The aim of this study is to determine the pulmonary functions in AS patients and to assess its relationship with quality of life, functionality and disease activity. Thirty-six AS patients and 34 healthy volunteers were recruited for the study. A detailed examination, pulmonary function tests, smoking inquiry and quality of life questionnaire were performed on all participants. Also patients were requested to complete functionality and disease activity indexes. The outcomes showed that $15(41.7 \%)$ AS patients had pulmonary involvement: twelve patients with restrictive patterns, one with obstructive pattern, and two with both restrictive and obstructive patterns. Decreased forced expiratory volume in one second was associated with deteriorated functionality $(p<0.05)$. Decreased chest expansion was also accompanied with decreased forced vital capacity $(p<0.05)$. There was no statistically significant difference between the smoking and non-smoking patients in regard to disease activity, functionality and pulmonary function test variables $(p>0.05)$. In conclusion, the pulmonary involvement is common in AS and might have disturbed functionality and the quality of life in AS patients. - rheumatic disease; ankylosing spondylitis; pulmonary involvement; functionality; quality of life

(C) 2007 Tohoku University Medical Press

Received January 29, 2007; revision accepted for publication June 26, 2007.

Correspondence: Dr. Umit Dincer, GATA Haydarpasa Egitim Hastanesi Fiziksel Tip ve Rehabilitasyon Servisi, 34668 Kadikoy, Istanbul, Turkey.

e-mail: drumitdincer@yahoo.com 
Rheumatic diseases are characterized by inflammation and loss of function of one or more connecting or supporting structures of the body. Some rheumatic diseases can also involve internal organs. Spondyloarthropaties are a group of rheumatic diseases that principally affect the spine and sacroiliac joints. One common form of spondyloarthropaties is ankylosing spondylitis (AS) which is a chronic, systemic, inflammatory rheumatic disease that affects mainly the axial skeleton and to a lesser degree, peripheral joints and certain extra-articular organs, including the lungs, eyes, and cardiovascular system. (Seçkin et al. 2000; El Maghraoui et al. 2003). The involvement of the lungs measured as reduced lung volumes is a known manifestation of the disease. This has been suggested to be a consequence of reduced mobility of the thoracic cage (Hamilton 1949; Hurwitz et al. 1982; Hillerdal 1983; Seçkin et al. 2000). In previous studies, which were made with reontgenographic evaluation, pulmonary involvement frequency was reported between 1 to $15 \%$ in AS in different studies (Rosenow et al. 1977; Fenlon et al. 1997). However in recent studies, which were performed with chest high resolution computed tomography, the pulmonery involvement freguency was reported between 40 to $80 \%$ in different studies (Fenlon et al. 1997; Turetschek et al. 2000; Kiris et al. 2003; Senocak et al. 2003; Souza et al. 2004; Sampaio-Barros et al. 2007). The pulmonary involvement in AS usually emerges either in the form of interstitial lung disease or in the form of restricted pulmonary functions due to chest wall limitation. The involvement of thoracic vertebrae, costovertebral costotransverse, sternoclavicular and sternomanubrial joints result in an increase in dorsal kyphosis and rigidity of the thorax (Fisher et al. 1990). However, nature, frequency and etiology of the pulmonary involvement in AS and its relationship with functionality, disease activity, quality of life and radiological status are not yet clearly elucidated. The aim of this study is to determine the pulmonary functions in AS patients and to assess its relationship with quality of life (QOL), functionality and disease activity.

\section{Materials and Methods}

Study design and patients

This was a cross-sectional study and approved by the Gulhane Military Medical Academy ethical committee. All of the recruited subjects signed the informed consent and agreed to participate. Thirty-six male patients with diagnosis of AS according to modified New York criteria and 34 age-matched healthy male volunteers with similar physical activity levels were recruited for this study. The controls were healthy subjects who visited our outpatient clinic for annual routine health control and they had no disease. The patients who had a systemic disorder that affects the locomotor system or had a chronic disease other than AS were excluded.

\section{Clinical assessments and laboratory parameters}

All of participants were examined by a physician, and their demographic characteristics and smoking were inquired. In addition, laboratory findings (hemogram, erythrocyte sedimentation rate [ESR], C-reactive protein [CRP], liver and renal function tests) and radiological findings (patients' chest, lumbosacral and sacro-iliac joint radiographies) were assessed. Furthermore, all participants' QOL and all patients' functionality and disease activity status were assessed with the following indexes: functional status with Bath Ankylosing Spondylitis Functional Index (BASFI) (Ozer et al. 2005), disease activity with Bath Ankylosing Spondylitis Disease Activity Index (BASDAI) (Yanik et al. 2005), and QOL with Short Form-36 (SF-36) (Demirsoy 1999).

BASFI consists of eight specific questions regarding functions and two questions reflecting the patient's ability to cope with daily life. BASDAI consists of six questions pertaining to the five major symptoms of AS. Each question was answered on a $10 \mathrm{~cm}$ horizontal visual analog scale (VAS). The higher the score means the greater the disability. SF-36 is a self-administered questionnaire assessing problems experienced during the previous four weeks in eight domains; physical functioning, pain, role limitations due to physical problems, role limitation due to emotional problems, social functioning, mental health, energy, and general health perceptions. Each domain is scored in a range between 0-100. The higher scores indicate better functions.

The chest expansion was measured with a tape measure (in $\mathrm{cm}$ ) placed circumferentially around the chest wall at the fourth intercostal space. The limitation in lumbar flexion was measured with a tape measure (modified Schober's test). Ten $\mathrm{cm}$ above and $5 \mathrm{~cm}$ below the 
dimples of Venus were marked. A restriction was considered if the distance between these points was less than $5 \mathrm{~cm}$ in maximal lumbar flexion. The smoking status was categorized as non-smoker, ex-smoker and current smoker (smoker was defined as a subject smoking at least one cigarette per day for a year). In order to calculate pack years of smoking, the average number of cigarettes smoked per day was divided by 20 to find packs per day and was then multiplied by the total number of years of smoking.

Pulmonary function test (PFT) was performed on all patients and controls by using PFT machine (Minato AS-600 spirometer, Minato, Osaka). This test is used for evaluation of lung volume and lung capacities that reflect airway and lung tissue diseases. The PFT results of the patient and control groups were recorded according to age, sex and height by using predicted percentages according to American Thoracic Society (ATS) criteria (ATS 1995). The following PFT parameters were determined:

-Forced vital capacity (FVC \%) was accepted as the total amount of air that could be forcibly blowed out after full inspiration.

-Forced expiratory volume during the first second (FEV1\%) was accepted as the amount of air that could be forcibly blow out in one second.

$-F E V 1 / F V C$ is a ratio showing the amount of the FVC that could be expelled at first second. For healthy adults this should be approximately $80 \%$.

-Forced expiratory flow at 50\% of vital capacity (FEF50) is similar to the peak expiratory flow (PEF), except the measurement is taken at the listed portion of the breath out.

-Vital capacity (VC) is the maximum volume that an individual could expire after a single maximal inspiration.

Three breathing patterns were defined:

-obstructive pattern, as $\mathrm{FEV}_{1} / \mathrm{FVC}<80 \%$,

-restrictive pattern, as decrease of $\mathrm{FVC}<80 \%$ and $\mathrm{FEV}_{1}$ with a normal $\mathrm{FEV}_{1} / \mathrm{FVC}$ ratio, $80 \%$.

-normal pattern as $\mathrm{FVC}>80 \%$ and $\mathrm{FEV}_{1} / \mathrm{FVC}>$

\section{Statistical analysis}

Statistical analyses were performed with SPSS 11.0. Descriptive data was presented as mean \pm S.D. Comparisons between the groups were performed by using Student t-test for continuous variables. Pearson's correlation coefficient was used to measure the correla- tions between AS indexes and SF-36, the chest expansion and PFT parameters (FVC, FEV1, FEV1/ FVC, forced expiratory flow rate, FEF50). The comparisons within groups were performed by using Mann Whitney's U-test. Statistical significance was set at $p<0.05$.

\section{Results}

The characteristics of all the subjects are shown in Table 1. There was no difference between patients and controls with regard to age, weight and body mass index. The mean chest expansion in AS patients was $3.9 \pm 2.2 \mathrm{~cm}$, which was significantly lower than that of controls $5.6 \pm$ $0.6 \mathrm{~cm}(p=0.002)$. In AS patients, all PFT parameters except FEV1/FVC were lower than those of controls' and the differences were statistically significant (all $p$ values $<0.05$ ). The $41.7 \%$ of the patients' PFT results were abnormal; 12 patients $(33.3 \%)$ had restrictive, one patient $(2.8 \%)$ had obstructive, two patients $(5.6 \%)$ had both restrictive and obstructive patterns, and 21 patients $(58.3 \%)$ were normal. Only two patients had abnormal chest radiographies: one apical fibrosis and one bronchiectasis.

Disease activity had not any relation with PFT variables. Also BASFI scores' relationships with PFT variables were investigated and it was found that functionality had no relationship with PFT variables except FEV1. FEV1 had statistically significant negative correlation with functionality for AS patients. This means that lower FEV1 values were together with higher functionality scores. ESR, CRP, the chest expansion and the modified lumbar schober were also compared to functionality and disease activity (Table 2). VC, FVC and FEV1 values were lower in the patients whose CRP values were higher. The VC values were also lower in the patients whose ESR values were higher.

The chest expansion in AS patients was significantly lower than the controls. Both FVC and VC were found decreased while the chest expansion decreased in AS patients $(\mathrm{r}=0.375 ; p=0.025$, $\mathrm{r}=0.384 ; p=0.024$; respectively).

Patients and controls were also investigated for smoking status. In patients group, the mean packs years were $12.0 \pm 5.8$. In control group, the 
TABle 1. Demographic and clinic features and, pulmonary function test results of both groups according to age, sex and height predicted percentages.

\begin{tabular}{|c|c|c|c|}
\hline & AS $(n=36)$ & Controls $(n=34)$ & $p$ value \\
\hline Age (Years) & $30.6 \pm 9.1$ & $28.6 \pm 7.2$ & 0.413 \\
\hline Height (cm) & $171.4 \pm 6.2$ & $170.1 \pm 4.8$ & 0.224 \\
\hline Weight (kg) & $78.4 \pm 11.2$ & $75.8 \pm 9.2$ & 0.440 \\
\hline BMI $\left(\mathrm{kg} / \mathrm{cm}^{2}\right)$ & $27.1 \pm 3.4$ & $26.2 \pm 4.0$ & 0.642 \\
\hline \multirow[t]{3}{*}{ Smoking status } & 21 current smoker & 17 current smoker & \\
\hline & 7 ex-smoker & 6 ex-smoker & \\
\hline & 8 non- smoker & 11 non- smoker & \\
\hline Schober $(\mathrm{cm})$ & $3.2 \pm 1.6$ & - & \\
\hline Chest Expansion $(\mathrm{cm})$ & $3.9 \pm 2.1$ & $5.6 \pm 0.6$ & $0.002^{a}$ \\
\hline M.lumbar schober & $4.5 \pm 2.2$ & - & \\
\hline BASFI & $4.3 \pm 2.3$ & - & \\
\hline BASDAI & $4.9 \pm 2.1$ & - & \\
\hline CRP & $21.6 \pm 35.0$ & - & \\
\hline ESR & $29.6 \pm 23.3$ & - & \\
\hline $\mathrm{VC}^{\mathrm{b}}$ & $76.9 \pm 16.5$ & $91.1 \pm 11.5$ & $0.002^{\mathrm{a}}$ \\
\hline $\mathrm{FVC}^{\mathrm{b}}$ & $86.7 \pm 15.9$ & $104.9 \pm 17.3$ & $0.001^{\mathrm{a}}$ \\
\hline FEV1 ${ }^{b}$ & $90.5 \pm 16.0$ & $111.4 \pm 15.8$ & $0.001^{\mathrm{a}}$ \\
\hline $\mathrm{FEV} / \mathrm{FVC}^{\mathrm{b}}$ & $104.3 \pm 8.9$ & $106.5 \pm 6.6$ & 0.223 \\
\hline
\end{tabular}

${ }^{\text {a }}$ Significant $(p<0.05)$.

$\mathrm{b} \%$ of the predicted value.

BASFI, Bath Ankylosing Spondylitis Functional Index; BASDAI, Bath Ankylosing Spondylitis Disease Activity Index; CRP, C-reactive protein; ESR, erythrocyte sedimentation rate; VC, vital capacity; FVC, forced vital capacity; FEV1, forced expiratory volume in one second.

TABLE 2. Correlation analysis ( $\mathrm{r}$ values) of laboratory and clinical features and pulmonary function tests in ankylosing spondylitis patients.

\begin{tabular}{llllll}
\hline & CRP & ESR & BASFI & BASDAI & $\begin{array}{c}\text { Chest } \\
\text { expansion }\end{array}$ \\
\hline VC & $-0.454\left(^{*}\right)$ & $-0.389\left(^{*}\right)$ & -0.092 & 0.072 & $0.384\left(^{*}\right)$ \\
FVC & $-0.412\left(^{*}\right)$ & -0.308 & -0.285 & -0.068 & $0.375\left(^{*}\right)$ \\
FEV1 & $-0.399\left(^{*}\right)$ & -0.355 & $-0.331\left(^{*}\right)$ & -0.146 & 0.302 \\
FEV1/FVC & 0.179 & -0.037 & -0.218 & -0.261 & -0.275 \\
\hline
\end{tabular}

*Correlation is significant at the 0.05 level (2-tailed).

BASFI, Bath Ankylosing Spondylitis Functional Index; BASDAI, Bath Ankylosing Spondylitis Disease Activity Index; CRP, C-reactive protein; ESR, erythrocyte sedimentation rate; VC, vital capacity; FVC, forced vital capacity; FEV1, forced expiratory volume in one second. 
mean packs per years were $10.4 \pm 6.1$. There were no statistically significant differences between smoker and non-smoker groups according to disease activity, functionality and PFT variables $(p>0.05)$.

PFT variables were compared to SF-36 scores in order to reveal the relation with quality of life in AS patients. Each SF-36 domain in AS patients was lower than those of controls $(p<$ 0.05). All QOL domains except the role limitations due to emotional problems were found to correlate positively with the functionality and correlate negatively with disease activity $(p<0.05)$. Thus, the patients whose disease activity levels were higher and functionality levels were lower, quality of life were worse in general. There were no statistically significant correlation between the QOL domains and PFT variables (Table 3). Also, QOL domains were found to be indifferent between patients with restrictive lung involvement and those who had normal PFTs.

Patients with restrictive PFT pattern and those who had normal PFT pattern were also compared with regard to chest expansion, functionality and disease activity. Statistically significant difference was observed only in chest expansion $(p=0.001)$. Patients who had restrictive
PFT pattern chest expansion were lower than nromal PFT patterned patients.

\section{Discussion}

The pleuropulmonary abnormalities caused by AS have been known for many years. However, information about relationship between AS and respiratory functions is insufficient. The pulmonary function tests in AS had shown previously that the typical pattern was restrictive, characterized by a low thoracic expansion, but pulmonary compliance, diffusion capacity and arterial blood gases were normal (Fisher et al. 1990). The restrictive pattern characterized by low FVC is frequently associated with low thoracic expansibility (Feltelius et al. 1986; Franssen et al. 1986; Vanderschueren et al. 1989). The normal chest expansion requires normal costovertebral, costosternal, manubriosternal and sternoclavicular joints. If any of these joints are involved, the chest expansion is decreased. Cerrahoglu et al. (2002) reported that sacroiliac joint and costovertebral joint involvement showed a statistically significant correlation with decreased chest expansion, longer disease duration and increased morning stiffness in AS. They have found that neither obstructive nor restrictive respiratory

TABLE 3. Correlations ( $\mathrm{r}$ values) between quality of life scores and functionality, disease activity and pulmonary function tests.

\begin{tabular}{llllrrr}
\hline & BASFI & BASDAI & VC & FVC & FEV1 & FEV1/FVC \\
\hline Physical functioning & $0.562(\ddagger)$ & $-0.470(\ddagger)$ & 0.104 & 0.092 & 0.188 & 0.181 \\
Role limitations & $0.599(\ddagger)$ & $-0.647(\ddagger)$ & 0.174 & 0.105 & 0.120 & 0.003 \\
Bodily pain & $0.556(\ddagger)$ & $-0.645(\ddagger)$ & 0.077 & -0.026 & 0.050 & 0.124 \\
Social functioning & $0.466(\ddagger)$ & $-0.548(\ddagger)$ & 0.235 & 0.296 & 0.267 & -0.095 \\
General mental health & $0.347(\dagger)$ & $-0.503(\ddagger)$ & 0.163 & 0.115 & 0.088 & -0.077 \\
Role limitations-due to & 0.263 & -0.287 & 0.147 & -0.040 & -0.032 & 0.001 \\
emotional problems & & & & & & \\
Vitality, energy or fatigue & $0.540(\ddagger)$ & $-0.604(\ddagger)$ & 0.158 & 0.334 & 0.268 & -0.078 \\
General health perceptions & $0.566(\ddagger)$ & $-0.546(\ddagger)$ & 0.059 & 0.190 & 0.237 & 0.141 \\
\hline
\end{tabular}

$\$$ Correlation is significant at the 0.01 level (2-tailed).

$\dagger$ Correlation is significant at the 0.05 level (2-tailed).

BASFI, Bath Ankylosing Spondylitis Functional Index; BASDAI, Bath Ankylosing Spondylitis Disease Activity Index; CRP, C-reactive protein; ESR, erythrocyte sedimentation rate; VC, vital capacity; FVC, forced vital capacity; FEV1, forced expiratory volume in one second. 
function abnormality was detected in the PFT. In addition, they observed that PFT values had no significant relation with involvement of costotransverse and costovertebral joints, decreased chest expansion and hand-ground distance. They also found that the morning stiffness lasting more than $30 \mathrm{~min}$ and hand ground distance were reported to be good indicators of disease activity. Opposingly, we found that decreased chest expansion had significant correlation with decreased VC and FVC values. But, more importantly, we found that $41.7 \%$ of our patients had abnormal PFT patterns and mostly restrictive lung disease pattern. We do not have a reasonable explanation for this significant difference between the two studies. On the other hand, in accordance with our results, there are some studies in the literature (El Maghraoui et al. 2004; Sahin et al. 2004) that show restrictive PFT pattern in AS patients.

It is known that functionality in AS patients is lower than the healthy people and this may somewhat be related to the pulmonary involvement. Sahin et al. (2004) stated that there was a significant negative correlation between functionality and pulmonary muscle strength, but they did not find a significant relation between BASFI and the chest expansion. They also concluded that chest expansion did not affect the functionality. Their results are similar to ours; we found that chest expansion had no relationship with functionality, disease activity and QOL in AS patients. In our study, it was shown that there was no difference with regard to functionality scores, between those patients having restrictive PFT pattern and those having normal pattern. Fisher et al. (1990) showed that AS patients with very restricted chest expansion were able to achieve adequate work capacities. Ariza-Ariza et al. (2003) investigated QOL and functionality in AS patients and they found that disease activity and restriction of axial joints were the main related factors with physical function. This condition might reflect that chest limitation does not contribute to diminished functionality in AS patients. Ward et al. (2005) studied 326 patients with AS -of at least 20 years of disease duration- to investigate the risk factors for functional limitations. Lifetime occu- pational physical activity, current smoking, education level, number of co-morbid conditions, and family history were found to be significantly associated with functionality. But we did not find any relation with smoking status and functionality. El Maghraoui et al. (2004) compared lung findings on thoracic HRCT to PFT findings to find out if there was any correlation in AS patients. They reported that the pulmonary function was not related to parenchymal lesions but correlated with axial joint involvements and disease activity. Similar to our study, they found that PFT was related to functionality. In contrast to our study, they did not find any correlation between PFT and thoracic expansion. Casserly et al. (1997) reported that the patients who had PFT abnormality shown abnormal HRCT changes and there was a statistically significant correlation with HRCT and PFT findings.

The pulmonary involvement in the AS is various. However, the presence of a clinical or subclinical lung involvement is not correlated to disease activity, ventilatory dysfunction or medication. Diaphragmatic respiration is the main compensation mechanism to prevent restrictive respiration pattern. When chest expansion decreases, diaphragm, sternocleidomastoid, pectoral and scalen muscles activities increase and compensate for restrictive changes. The concordance between PFT results and functional may be related to this condition.

We found a few studies investigating the relationship between QOL and PFTs in patients with chronic diseases. In the study by Euteneuer et al. (2006), QOL was found to be worse in patients with chronic obstructive pulmonary disease (COPD) and neuromuscular diseases, but not in patients with restrictive ventilatory disorders. These results are partly similar to ours, because there was no difference between QOL in patients having restrictive PFT pattern and those having normal PFT pattern despite QOL was worse in AS patients than controls. Soyyigit et al. (2006) reported that there was only a moderate positive correlation between pulmonary functions (FVC and FEV1) and general health perception and physical function in COPD patients. These results 
support that COPD and restrictive pulmonary disease disturb the quality of life but they are not strongly related to pulmonary functions.

The role of smoking in worsening lung disease in AS patients is plausible. However, we found no difference between PFT results of smokers and non-smokers. Likewise, El Maghraoui (2005) found that HRCT abnormalities were similar between smoker vs nonsmoker AS patients.

In conclusion, the restrictive pulmonary involvement is common in AS patients but its reason is not definitely known. The restrictive pattern at PFT might be associated with low thoracic expansibility and decreased vertebral column mobility, but there is no sufficient proof to confirm this relationship yet. It is clear that the QOL and functionality are worsened in AS, however; restrictive pulmonary pattern alone does not worsen the QOL and functionality scores in these patients. Further, the pulmonary volume and capacities seem not to reflect the functionality, QOL and disease activity in AS. We conclude that the vertebral mobility and the chest expansibility are important for pulmonary functions in AS patients and PFT may be useful to assess the pulmonary functions in this regard.

\section{References}

American Thoracic Society (ATS) (1995) Standardization of Spirometry, 1994 Update. Am. Respir. Crit. Care Med., 15, 1107-1136.

Ariza-Ariza, R., Hernandez-Cruz, B. \& Navarro-Sarabia, F. (2003) Physical function and health-related quality of life of Spanish patients with ankylosing spondylitis. Arthritis Rheum., 49, 483-487.

Casserly, I.P., Fenlon, H.M., Breatnach, E. \& Sant, S.M. (1997) Lung findings on high-resolution computed tomography in idiopathic ankylosing spondylitis-correlation with clinical findings, pulmonary function testing and plain radiography. Rheumatology, 36, 677-682.

Cerrahoglu, L., Unlu, Z., Can, M., Goktan, C. \& Celik, P. (2002) Lumbar stiffness but not thoracic radiographic changes relate to alteration of lung function tests in ankylosing spondylitis. Clin. Rheumatol., 21, 275-279.

Demirsoy, A.C. (1999) The MOS SF-36 health survey: a validation study with a Turkish sample. Thesis, Bogazici University, Istanbul.

El Maghraoui, A., Bensabbah, R., Bahiri, R., Bezza, A., Guedira, N. \& Hajjaj-Hassouni, N. (2003) Cervical spine involvement in ankylosing spondylitis. Clin. Rheum., 22, 94-98.

El Maghraoui, A., Chaouir, S., Abid, A., Bezza, A., Tabache, F., Achemlal, L., Abouzhair, A., Ghafir, D., Ohayan, V. \&
Archane, M.I. (2004) Lung findings on thoracic high-resolution computed tomography in patients with ankylosing spondylitis. Correlations with disease duration, clinical findings and pulmonary function testing. Clin. Rheumatol., 23, 123-128.

El Maghraoui, A. (2005) Pleuropulmonary involvement in ankylosing spondylitis. Joint Bone Spine, 72, 496-502.

Euteneuer, S., Windisch, W., Suchi, S., Köhler, D., Jones, P.W. \& Schonhofer, B. (2006) Health-related quality of lifein patients with chronic respiratory failure after long-term mechanical ventilation. Respir. Med., 3, 477-486.

Feltelius, N., Hedenstrom, H., Hillerdal, G. \& Hallgren, R. (1986) Pulmonary involvement in ankylosing spondylitis. Ann. Rheum. Dis., 45, 736-740.

Fenlon, H.M., Casserly, I., Sant, S.M. \& Breatnach, E. (1997) Plain radiographs and thoracic high-resolution $\mathrm{CT}$ in patients with ankylosing spondylitis. Am. J. Roentgenol., 168, 1067-1072.

Fisher, L.R., Cawley, M.I.D. \& Holgate, S.T. (1990) Relation between chest pain expansion pulmonary function and exercise tolerance in patients with ankylosing spondylitis. Ann. Rheum. Dis., 49, 921-925.

Franssen, M.J.A.M., Van Herwaarden, C.L.A., Van de Putte, L.B.A. \& Gribnau, F.W.J. (1986) Lung function in patients with ankylosing spondylitis. A study of the influence of disease activity and treatment with non-steroidal antiinflammatory drugs. J. Rheumatol., 13, 936-940.

Hamilton, K.A. (1949) Pulmonary disease manifestations of ankylosing spondylitis. Ann. Int. Med., 31, 216-227.

Hillerdal, G. (1983) Ankylosing spondylitis lung disease is an underdiagnosed entity? Eur. J. Respir. Dis., 64, 437-441.

Hurwitz, S.S., Conlan, A.A. \& Krige, L.P. (1982) Fibrocavitating pulmonary lesions in ankylosing spondylitis. S. Af. Med. J., 61, 168-170.

Kiris, A., Ozgocmen, S., Kocakoc, E., Ardıcoglu, O. \& Ogur, E. (2003) Lung findings on high resolution CT in early ankylosing spondylitis. Eur. J. Radiol., 47, 71-76.

Ozer, H.T., Sarpel, T., Gulek, B., Alparslan, Z.N. \& Erken, E. (2005) The Turkish version of the Bath Ankylosing Spondylitis Functional Index: reliability and validity. Clin. Rheumatol., 24, 123-128.

Rosenow, E.C., Strimlan, C.V., Muhm, J.R. \& Ferguson, R.H. (1977) Pleuropulmonary manifestations of ankylosing spondylitis. Mayo Clin. Proc., 52, 641-649.

Sahin, G., Calikoglu, M., Ozge, C., Incel, N., Bicer, A., Ulubas, B. \& Guler, H. (2004) Respiratory muscle strength but not BASFI score relates to diminished chest expansion in ankylosing spondylitis. Clin. Rheumatol., 23, 199-202.

Sampaio-Barros, P.D., Cerqueira, E.M., Rezende, S.M., Maeda, L., Conde, R.A., Zanardi, V.A., Bertolo, M.B., de Menezes, Neto, J.R. \& Samara, A.M. (2007) Pulmonary involvement in ankylosing spondylitis. Clin. Rheumatol., 26, 225-230.

Seçkin, Ü., Bölükbasi, N., Gürsel, G., Eröz, S., Sepici, V. \& Ekim, N. (2000) Relationship between pulmonary function and exercise tolerance in patients with ankylosing spondylitis. Clin. Exp. Rheumatol., 18, 503-506.

Senocak, O., Manisali, M., Ozaksoy, D., Sevinc, C. \& Akalin, E. (2003) Lung parenchyma changes in ankylosing spondylitis: demonstration with high resolution $\mathrm{CT}$ and correlation with disease duration. Eur. J. Radiol., 45, 117-122.

Souza, A.S., Muller, N.L., Marchiori, E., Soares-Souza, L.V. \& de Souza Rocha, M. (2004) Pulmonary abnormalities in ankylosing spondylitis: inspiratory and expiratory highresolution CT findings in 17 patients. J. Thorac. Imaging, 
19, 259-263.

Soyyigit, S., Erk, M., Guler, N. \& Kilinc, G. (2006) The value of SF-36 questionnaire for the measurement of life quality in chronic obstructive pulmonary disease. Tuberk. Toraks., 54, 259-266.

Turetschek, K., Ebner, W., Fleischmann, D., Wunderbaldinger, P., Erlacher, L., Zontsich, T. \& Bankier, A.A. (2000) Early pulmonary involvement in ankylosing spondylitis: assessment with thin-section CT. Clin. Radiol., 55, 632-636.

Vanderschueren, D., Decramer, M., Van den Daele, P. \& Dequeker, J. (1989) Pulmonary functionand maximal tran- srespiratory pressures in ankylosing spondylitis. Ann. Rheum. Dis., 48, 632-635.

Ward, M., Weisman, M.H., Davis, J.C. \& Reveille, J.D. (2005) Risk factors for functional limitations in patients with long-standing ankylosing spondylitis. Arthritis Care Res., 5, 710-717.

Yanik, B., Gursel, Y.K., Kutlay, S., Ay, S. \& Elhan, A.H. (2005) Adaptation of the Bath Ankylosing Spondylitis Functional Index to the Turkish population, its reliability and validity: functional assessment in AS. Clin. Rheumatol., 24, 41-47. 